\title{
Psychological processes in bipolar affective disorder: negative cognitive style and reward processing
}

\author{
Emma Van der Gucht, Richard Morriss, Gill Lancaster, Peter Kinderman and Richard P. Bentall
}

\section{Background}

Psychological processes in bipolar disorder are of both clinical and theoretical importance.

\begin{abstract}
Aims
To examine depressogenic psychological processes and reward responsivity in relation to different mood episodes (mania, depression, remission) and bipolar symptomatology.
\end{abstract}

\section{Method}

One hundred and seven individuals with bipolar disorder (34 in a manic/hypomanic or mixed affective state; 30 in a depressed state and 43 who were euthymic) and 41 healthy controls were interviewed with Structured Clinical Interview for DSM-IV and completed a battery of self-rated and experimental measures assessing negative cognitive styles, coping response to negative affect, self-esteem stability and reward responsiveness.

\section{Results}

Individuals in all episodes differed from controls on most depression-related and reward responsivity measures. However, correlational analyses revealed clear relationships between negative cognitive styles and depressive symptoms, and reward responsivity and manic symptoms.

\section{Conclusions}

Separate psychological processes are implicated in depression and mania, but cognitive vulnerability to depression is evident even in patients who are euthymic.

\section{Declaration of interest}

None. Funding detailed in Acknowledgements.
Progress in understanding the role of psychological processes in bipolar disorder may facilitate the development of interventions for people with this highly disabling illness and also research on underlying biological mechanisms, for example by identifying candidate endophenotypes or by providing targets for neuroimaging studies. Some studies have identified depression-related psychological abnormalities in people with bipolar disorder, for example low ${ }^{1}$ or unstable self-esteem, ${ }^{2}$ rumination, ${ }^{3}$ dysfunctional attitudes to self-evaluation ${ }^{4}$ and a pessimistic explanatory style, ${ }^{5}$ which have sometimes been interpreted as evidence that mania arises from dysfunctional strategies for avoiding depression. ${ }^{3}$ Other studies have found that manic episodes are preceded by goal attainment life events, ${ }^{6}$ suggesting that excessive reward responsiveness ${ }^{7}$ may be important in the condition. It is not clear whether these mechanisms are trait vulnerability factors or related to symptoms and episodes. To answer this question we administered multiple measures of depressogenic cognitive biases and reward responsivity to people with bipolar disorder who had remitted, were currently depressed or were currently manic and healthy controls. We predicted that depressive symptoms would be specifically related to depressogenic cognitive styles and manic symptoms would be specifically related to reward responsivity.

\section{Method}

The design was a cross-sectional study with four groups broadly matched for age, gender and premorbid intelligence.

\section{Participants}

One hundred and seven people with bipolar disorder were recruited from across the North West of England. Potential in-patients were identified and approached by either their consultant psychiatrist or the senior nurse in charge on participating wards. Potential out-patients were identified and approached by their consultant psychiatrist, community mental health team keyworker or lithium clinic doctor to obtain verbal consent to be approached by the researcher. Adverts were also placed in out-patient waiting areas, day hospitals and Pendulum (the Manic Depression Fellowship quarterly magazine for service users).

The inclusion criteria for the patient sample were: a DSM-IV ${ }^{8}$ diagnosis of bipolar disorder; age 18 years or over; ability to read and write English; and willingness to give written informed consent to the study. Diagnoses were confirmed by Structured Clinical Interview for DSM-IV (SCID) ${ }^{9}$ and the intellectual comparability of the groups was assessed using the National Adult Reading Test. ${ }^{10}$ Individuals were excluded if they had a clear organic cause for their disorder or medical comorbidity that put the diagnosis of any bipolar episode in the past 24 months in doubt. Thirty-four participants were allocated to the mania group because they met DSM-IV criteria for manic or hypomanic episode (31) or mixed affective state (3); 30 to the depression group because they met DSM-IV criteria for major depressive episode; and 43 to the remitted group because they had not met DSM-IV criteria for a major depressive, hypomanic, mixed affective or manic episode in the past 2 months and also had a Hamilton Rating Scale for Depression (HRSD) $)^{11}$ score of eight or less and a score on the Mania Rating Scale $(\mathrm{MRS})^{12}$ of three or less.

Forty-one healthy controls were recruited via adverts placed around the Royal Liverpool University Hospital, in local libraries, and on the University of Liverpool staff internet message board. Inclusion criteria were not meeting SCID criteria for any psychiatric disorder within the last 2 years; age 18 years or over; ability to read and write English; and willingness to give written informed consent to the study. 


\section{Procedures}

The study was approved by a National Health Service Multi-centre Research Ethics Committee in accordance with the Helsinki Declaration of 1975 . Once the suitability of participants had been confirmed by SCID, participants were administered the HRSD, the Bech-Rafaelsen Mania Rating Scale ${ }^{12}$ and the Cassidy Scale for Manic States. ${ }^{13}$ Assessments were then conducted within the following 7 days in meetings between 11:00 and 18:00 to control for diurnal mood variation in the following order: Personal Style Inventory (PSI); ${ }^{14}$ Behavioural Inhibition System/Behavioural Activation System Scales (BIS/BAS); ${ }^{15}$ Autobiographical Memory; ${ }^{16}$ Pragmatic Inference Task (PIT) ${ }^{17}$ Rosenberg Self-Esteem Scale (RSE); ${ }^{18}$ Modified Response Style Questionnaire (RSQ); ${ }^{19}$ Card Arranging Reward Responsivity Objective Test (CARROT); ${ }^{20}$

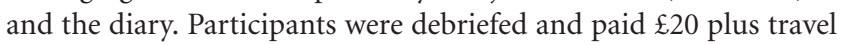
expenses.

\section{Psychological measures}

The following psychological measures were used.

(a) The Personality Style Inventory (PSI) $)^{14}$ is a 48 -item selfschema measure with sub-scales of autonomy and sociotropy.

(b) The Behavioural Inhibition System/Behavioural Activation System scale $(\mathrm{BIS} / \mathrm{BAS})^{15}$ has 20 items with sub-scales measuring behavioural inhibition and three scores for behavioural activation; drive, reward responsiveness and fun seeking.

(c) Autobiographical Memory was assessed using the method of Williams \& Broadbent. ${ }^{16}$ Participants attempted to retrieve specific memories to six positive and six negative cue words. Memories were categorised as general extended (e.g. 'The last time I was in hospital'); general categorical (e.g. 'When I go to the park'); specific (a memory linked to a particular occasion) or delusional. Reliability of the classification was good $(96 \%$ agreement between independent raters on the first 50 participants).

(d) The Pragmatic Inference Task (PIT) ${ }^{17}$ is an implicit measure of attributional (explanatory) style, giving internality scores for positive and negative events.

(e) The Rosenberg Self-Esteem Scale (RSE) ${ }^{18}$ is a widely used 10item self-reported measure of self-esteem.

(f) Modified Response Style Questionnaire (RSQ) ${ }^{19}$ is a 38 -item questionnaire with sub-scales measuring rumination, adaptive coping (distraction and problem solving), and risk-taking.

(g) The Card Arranging Reward Responsivity Objective Test $(\mathrm{CARROT})^{20}$ is a three-trial card sorting task. On the third trial participants receive monetary reward for speed and increased speed in this trial is taken as a measure of reward responsivity.

(h) Participants completed a self-esteem diary ${ }^{2,21}$ twice daily for 4 consecutive days at approximately 10:00 and at 22:00. At each time, participants completed the RSE and the Positive and Negative Affect Scale, ${ }^{22}$ a brief measure of mood. Withinparticipant standard deviations (s.d.'s) were calculated as a measure of variability on these scales.

\section{Statistical analysis}

Analyses were carried out using SPSS 14 for Windows. Groups were compared with ANOVA followed by post hoc Tukey honestly significant difference (HSD) tests. Partial correlations were used to examine relationships between psychological measures and symptom scores, controlling for Bech-Rafaelsen scores when analysing relationships with depression, and controlling for HRSD scores when examining relationships with mania. Factor analysis (principal components with varimax rotation) on the psychological measures from the complete sample of 148 was then used to reduce the 17 psychological measures to a minimum number of dimensions, which were then compared between groups. The ratio of sample size to measures, approximately 9:1 exceeded the recommended minimum of $5: 1 .^{23}$

\section{Results}

\section{Demographic and clinical measures}

Demographic and clinical data are shown in online Table DS1 and Table 1, which also give the results of univariate tests. No differences were observed between the groups for age, IQ, the proportion of males or educational achievement, but the people in the bipolar groups were less likely to be employed and more likely to be living alone compared with the controls. The mania group scored higher on the Bech-Rafaelsen Scale compared with all other groups (minimum $P<0.0001$ ). On the HRSD, the depression group scored higher than all other groups $(P$ at least $<0.001$ ) but the mania group scored higher than both the euthymia group and controls $(P$ at least $<0.001)$. An identical pattern was observed on the Cassidy negative mood sub-scale. On the psychomotor agitation, psychosis and increased hedonic functioning Cassidy sub-scales the mania group scored higher than all other groups $(P$ at least $<0.001)$. Finally, on the Cassidy paranoia sub-scale, the mania and depression groups scored higher than the euthymia and control groups $(P$ at least $<0.05)$ but not differently from each other.

Diary mood scores are also shown in Table 1. People in the mania group reported more positive affect than those in the euthymia $(P<0.01)$ and depression groups $(P<0.001)$, who reported less positive affect than the euthymia $(P<0.01)$ and control groups $(P<0.001)$. All three bipolar disorder groups reported higher negative affect than the control group $(P<0.001$ for all comparisons) and the depression group reported more negative affect than both the mania $(P<0.001)$ and euthymia groups $(P<0.001)$, who did not differ on this measure. No differences were observed in variability of positive affect (measured by the within-participant standard deviation of scores) but the depression $(P<0.001)$ and mania groups $(P<0.005)$ had greater variability in negative affect than the control group, and the depression group also showed greater variability in negative affect than the euthymia group $(P<0.01)$.

\section{Depression-related psychological measures}

Scores for depressogenic cognitive style are shown in Table 2. Significant main effects were observed on all measures with the exception of the PIT and RSQ adaptive coping. All bipolar groups scored higher than the control group on sociotropy and autonomy $(P<0.0001$ for each comparison $)$ and the depression group scored higher than the euthymia group on sociotropy $(P<0.001)$. The control group reported higher self-esteem on the RSE than all three patient groups $(P$ at least $<0.005)$ but the mania and euthymia groups scored higher than the depression group $(P<0.001$ for each comparison). On the twice daily ratings of self-esteem, post hoc analysis revealed that the depression group had a lower mean score than all the other groups $(P$ at least $<0.005$ level) and the euthymia group had a lower mean score than the control group $(P<0.05)$ but there was no significant difference between the controls and mania groups. The control group also showed less variability (as measured by the within-participant standard deviation of scores) in self-esteem compared with the 
Table 1 Mean $(95 \% \mathrm{Cl})$ scores and F-values of participants in the three bipolar disorder groups and the control group on the study instruments

\begin{tabular}{|c|c|c|c|c|c|c|}
\hline & $\begin{array}{c}\text { Control } \\
\text { Mean }(95 \% \mathrm{Cl})\end{array}$ & $\begin{array}{c}\text { Euthymia } \\
\text { Mean }(95 \% \mathrm{Cl})\end{array}$ & $\begin{array}{c}\text { Depression } \\
\text { Mean }(95 \% \mathrm{Cl})\end{array}$ & $\begin{array}{c}\text { Mania/mixed } \\
\text { Mean }(95 \% \mathrm{Cl})\end{array}$ & $F$ & Tukey HSD \\
\hline Hamilton Depression Rating Scale & $1.61(0.98-2.24)$ & $3.49(2.60-4.38)$ & $19.50(16.81-22.19)$ & $8.45(6.36-10.54)$ & $98.39^{*}$ & $D>M>E=C$ \\
\hline Bech-Refaelson Mania Rating Scale & $1.15(0.79-1.50)$ & $1.72(1.16-2.28)$ & $3.03(2.20-3.87)$ & $15.48(12.93-18.04)$ & $115.02^{*}$ & $\mathrm{M}>\mathrm{D}=\mathrm{E}=\mathrm{C}$ \\
\hline \multicolumn{7}{|l|}{ Cassidy } \\
\hline Negative mood & $0.39(0.19-0.59)$ & $1.33(0.70-1.95)$ & $10.66(8.60-12.71)$ & $3.53(2.20-3.87)$ & $71.44^{*}$ & $D>M>E=C$ \\
\hline Agitation & $0.41(0.18-0.65)$ & $0.58(0.24-0.92)$ & $1.28(0.86-1.69)$ & $7.62(6.21-9.03)$ & $93.28^{*}$ & $\mathrm{M}>\mathrm{D}=\mathrm{E}=\mathrm{C}$ \\
\hline Psychosis & $0.15(0.01-0.28)$ & $0.35(0.02-0.68)$ & $1.31(0.62-2.00)$ & $5.15(3.93-6.36)$ & $51.06^{*}$ & $\mathrm{M}>\mathrm{D}=\mathrm{E}=\mathrm{C}$ \\
\hline Hedonic functioning & $0.32(0.14-0.50)$ & $0.35(0.07-0.62)$ & $0.41(0.05-0.77)$ & $4.26(3.34-5.19)$ & $63.05^{*}$ & $\mathrm{M}>\mathrm{D}=\mathrm{E}=\mathrm{C}$ \\
\hline Paranoia & $0.10(0.00-0.19)$ & $0.21(0.02-0.39)$ & $1.14(0.52-1.75)$ & $1.91(1.13-2.70)$ & $14.78^{\star}$ & $\mathrm{M}=\mathrm{D}>\mathrm{E}=\mathrm{C}$ \\
\hline \multicolumn{7}{|l|}{ Diary } \\
\hline Mean positive affect & $28.07(25.82-30.31)$ & $24.28(22.30-26.24)$ & $18.40(15.96-20.84)$ & $30.43(23.94-26.78)$ & $13.88^{*}$ & $M>E=C>D$ \\
\hline Mean negative affect & $11.35(10.74-11.96)$ & $14.06(12.64-15.47)$ & $21.89(18.81-24.96$ & $15.74(13.68-17.79$ & $27.05^{*}$ & $D>M=E>C$ \\
\hline Variability in positive affect & $5.54(4.85-6.22)$ & $5.18(4.41-5.94)$ & $5.64(3.99-7.28)$ & $4.99(3.60-6.39)$ & 0.32 & \\
\hline Variability in negative affect & $1.47(0.85-2.08)$ & $2.88(1.99-3.78)$ & $5.11(4.04-6.19)$ & $4.00(2.54-5.46)$ & $10.97 *$ & $M=D>C=E$ \\
\hline
\end{tabular}

\begin{tabular}{|c|c|c|c|c|c|c|}
\hline & $\begin{array}{c}\text { Control } \\
\text { Mean }(95 \% \mathrm{Cl})\end{array}$ & $\begin{array}{c}\text { Euthymia } \\
\text { Mean }(95 \% \mathrm{Cl})\end{array}$ & $\begin{array}{c}\text { Depression } \\
\text { Mean }(95 \% \mathrm{Cl})\end{array}$ & $\begin{array}{c}\text { Mania/mixed } \\
\text { Mean }(95 \% \mathrm{Cl})\end{array}$ & $F$ & $\begin{array}{l}\text { Tukey } \\
\text { HSD }\end{array}$ \\
\hline \multicolumn{7}{|l|}{ Personal Style Inventory } \\
\hline Sociotropy & $78.76(73.33-84.18)$ & $94.23(88.17-100.29)$ & $110.77(104.94-116.60)$ & $99.88(93.60-106.16)$ & $20.10^{* * *}$ & $D>E=M>C$ \\
\hline Autonomy & $72.24(67.36-77.13)$ & 88.44 (83.37-93.91) & 97.37 (91.60-103.13) & $92.64(87.01-98.26)$ & $17.60^{* * *}$ & $\mathrm{M}=\mathrm{D}=\mathrm{E}>\mathrm{C}$ \\
\hline Rosenberg Self-Esteem Scale & $25.73(24.50-26.97)$ & $20.37(18.42-22.33)$ & $12(9.64-14.36)$ & $21(18.74-23.26)$ & $32.174^{\star * *}$ & $\mathrm{C}>\mathrm{M}=\mathrm{E}>\mathrm{D}$ \\
\hline \multicolumn{7}{|l|}{ Diary self-esteem } \\
\hline Mean & $24.48(23.46-25.49)$ & $21.38(19.95-22.81)$ & $12.65(10.64-15.39)$ & $22.74(20.47-25.01)$ & $34.62^{\star * *}$ & $\mathrm{C}=\mathrm{M}>\mathrm{E}>\mathrm{D}$ \\
\hline Variability & $1.76(1.43-2.09)$ & $2.76(2.21-3.30)$ & $3.09(2.31-3.86)$ & $2.62(1.86-3.37)$ & $4.49^{* *}$ & $D=E>C$ \\
\hline \multicolumn{7}{|c|}{ Pragmatic Inference Task, internality } \\
\hline Negative events & $2.50(1.75-2.60)$ & $2.83(1.81-2.59)$ & $2.64(2.21-3.15)$ & $3.00(1.87-2.82)$ & 0.92 & \\
\hline Positive events & $2.17(2.02-2.98)$ & $2.20(2.42-3.23)$ & $2.68(2.17-3.12)$ & $1.34(2.53-3.47$ & 1.05 & \\
\hline \multicolumn{7}{|l|}{ Autobiographical memory a } \\
\hline Negative & $4.26(3.76-4.75)$ & $3.35(2.82-3.88)$ & $3.22(2.55-3.88)$ & $2.45(1.80-3.10)$ & $7.25^{\star \star *}$ & $\mathrm{C}>\mathrm{M}$ \\
\hline Positive & $2.92(2.40-3.45)$ & $2.68(2.20-3.15)$ & $2.74(2.10-3.38)$ & $2.28(1.66-2.89)$ & 0.98 & \\
\hline \multicolumn{7}{|l|}{ Response Styles Questionnaire } \\
\hline Rumination & $13.43(10.49-16.36)$ & $26.26(22.94-29.58)$ & $33.41(28.37-38.46)$ & $26.75(22.22-31.28)$ & $19.54^{* * *}$ & $D=M>E>C$ \\
\hline Adaptive coping & $15.83(13.51-18.14)$ & $13.29(10.07-15.50)$ & $12.31(10.05-14.57)$ & $15.22(12.60-17.84)$ & 1.91 & \\
\hline Risk taking & $0.73(0.32-1.13)$ & $1.48(0.88-2.08)$ & $1.79(1.00-2.59)$ & $2.25(1.38-3.12)$ & $3.98^{*}$ & $M>C$ \\
\hline
\end{tabular}

euthymia $(P<0.05)$ and depression groups $(P<0.05)$. No significant differences were observed on the PIT internality scores. On the autobiographical memory test, the mania group recalled fewer specific negative memories than the control group $(P<0.001)$ but no differences were observed for the recall of positive memories. On the RSQ, all three bipolar groups reported more rumination in response to negative mood than the controls $(P<0.001$ for all comparisons) and the euthymia group reported less rumination than the mania group $(P<0.05)$. No differences were reported for adaptive coping (distraction and problem-solving) but the mania group reported higher levels of risk-taking than the controls $(P<0.01)$.

\section{Reward processes}

Table 3 shows scores on the BIS/BAS scale and the CARROT. On the BIS (a measurement of sensitivity to punishment-related stimuli) the controls $(P<0.001$ for each comparison) and mania group $(P<0.05$ for each comparison) scored lower than the euthymia and depression groups. On BAS drive, the mania group scored higher than those in the depression $(\mathrm{P}<0.001)$ and euthymia groups $(P<0.05)$ but not the controls. On BAS fun seeking the mania group scored higher than the euthymia group $(P<0.05)$ but no differences were observed for the reward responsiveness sub-scale. No significant differences were observed on the CARROT.

\section{Relationships between psychological measures and symptoms}

Bech-Rafaelsen and HRSD scores were significantly correlated ( $r=0.24, \quad P<0.005$, d.f.=146). Therefore, partial correlations, shown in Table 4, were used to examine the relationships between psychological variables and mania and depression scores, in each case controlling for the effects of the other mood state. A clear pattern can be seen, with strong correlations between depression and measures of negative cognitive style (sociotropy, autonomy, self-esteem and rumination) and weaker correlations between 


\begin{tabular}{|c|c|c|c|c|c|c|}
\hline & $\begin{array}{c}\text { Control } \\
n(95 \% \mathrm{Cl})\end{array}$ & $\begin{array}{l}\text { Euthymia } \\
n(95 \% \mathrm{Cl})\end{array}$ & $\begin{array}{l}\text { Depression } \\
n(95 \% \mathrm{Cl})\end{array}$ & $\begin{array}{c}\text { Mania/mixed } \\
n(95 \% \mathrm{Cl})\end{array}$ & $F$ & $\begin{array}{l}\text { Tukey } \\
\text { HSD }\end{array}$ \\
\hline \multicolumn{7}{|l|}{ BIS/BAS scale } \\
\hline BIS & 18.85 (17.79-19.92) & $22.40(21.07-23.72)$ & $22.66(21.15-24.16)$ & $19.97(18.42-21.52)$ & $7.91 * * *$ & $\mathrm{D}=\mathrm{E}>\mathrm{M}=\mathrm{C}$ \\
\hline Drive & $9.95(9.05-10.81)$ & $9.72(8.91-10.53)$ & $8.66(7.55-9.76)$ & 11.65 (10.19-13.10) & $5.01 * *$ & $\mathrm{M}>\mathrm{D}=\mathrm{E}$ \\
\hline Fun seeking & $10.88(10.17-11.58)$ & $10.37(9.56-11.19)$ & $10.66(9.42-11.89)$ & $12.53(11.35-13.71)$ & $4.06^{*}$ & $M>E$ \\
\hline Reward responsiveness & 15.55 (14.74-16.38) & $15.72(14.91-16.53)$ & $15.66(14.50-16.81)$ & $16.24(15.03-17.44)$ & 0.38 & \\
\hline CARROT, reward responsivity & $3.59(1.95-5.22)$ & $2.49(0.11-4.87)$ & $5.03(1.32-7.38)$ & $4.35(1.30-8.76)$ & 0.73 & \\
\hline
\end{tabular}

manic symptoms and reward-related measures (the BAS scale, with a trend towards significance with the CARROT). These observations were confirmed using factor analysis (principal components with varimax rotation, missing data replaced by mean values) on all questionnaire measures and the CARROT, which yielded five easily interpretable factors: negative cognitive style (high loadings for sociotropy, autonomy, BIS and rumination, $22.5 \%$ of the variance), excitement (high loadings for the three BAS scores and RSQ risk taking, 18\%), PIT pessimism (internality for negative events, 10\%), PIT optimism (internality for positive events, 9\%) and CARROT scores (9\%); total variance accounted for $69.80 \%$. When these factor scores were partially correlated against the Bech-Rafaelsen and HRSD scores, the former robustly correlated with the excitement factor $(r=0.36, P<0.001$, d.f. $=144)$ but not the negative cognitive style factor $(r=-0.01, P=0.64$, d.f. $=144)$, whereas the latter robustly correlated with the negative cognitive style factor $(r=0.43$, $P<0.001$, d.f. $=144)$ but not the excitement factor $(r=-0.09$, $P=0.25$, d.f.=144).

Significant differences between the groups were observed for the negative cognitive style $(F(3,144)=22.32, P<0.001)$, excitement $(F(3,144)=5.69, P<0.001)$ and pessimism factors $(F(3,1444)=3.87$, $P=0.01)$. Interestingly, ANCOVA with Bech-Rafaelsen and HRSD scores as covariates revealed that the differences observed for negative cognitive style remained even after symptom scores were controlled for $(F(3,141)=10.08, P<0.001)$; planned contrasts revealed that both the euthymia $(P<0.0001)$ and depression groups $(P<0.0001)$ scored higher than the controls in this analysis. The group differences in excitement and pessimism did not remain after controlling for symptoms.

\section{Discussion}

In this study we aimed to investigate depressogenic cognitive styles and reward responsivity in a well-characterised and large sample of people diagnosed with bipolar disorder. When individuals in different episodes were compared with healthy controls, the results largely replicated those obtained in previous studies, with people with bipolar disorder in all phases showing high levels of sociotropy and autonomy and low self-esteem, ${ }^{4}$ self-esteem instability, ${ }^{2}$ rumination $^{3}$ and, less clearly, impairment in the ability to recall specific autobiographical memories. ${ }^{4}$ On all except the autobiographical memory measure, the euthymia group's results were abnormal compared with the controls. Less robust evidence of abnormal reward responsivity was evident in the group comparisons, but the mania group scored higher than the controls on two of the BAS scores (drive and fun seeking). Only the results from the PIT failed to replicate previous studies, which had indicated a pessimistic attributional style in patients with remitted ${ }^{2,17}$ and currently symptomatic bipolar disorder. ${ }^{5}$
A crucial issue when interpreting these and previous findings is the relationships between the measures and mood state. For example, previous reports of depressogenic processes during mania, ${ }^{5}$ although plausibly reflecting defensive processes, might more simply reflect the coactivation of depressogenic and reward-related processes in mixed episodes. Our factor analysis, which attempted to address this problem, yielded an easily interpretable model that accounted for a very large amount of the variance in the data. The high loadings of poor self-esteem, sociotropy, autonomy, BIS and rumination on a single factor suggest that these are highly related processes and might be considered to form a negative cognitive syndrome. The fact that the PIT and CARROT appeared as separate factors suggests that they are poor indicators of negative cognitive style and reward processing respectively, which probably accounts for their failure to discriminate between the groups.

A clear and specific relationship was observed between negative cognitive style and depression. However, it is notable that

Table 4 Partial correlations between mania and depression scores and the psychological measures (patients only, $n=107$ )

\begin{tabular}{|c|c|c|}
\hline & $\begin{array}{c}\text { Bech-Rafaels } \\
\text { mania }^{a}\end{array}$ & $\mathrm{HRSD}^{\mathrm{b}}$ \\
\hline \multicolumn{3}{|l|}{ Personal Style Inventory } \\
\hline Sociotropy & 0.06 & $0.31 * * * *$ \\
\hline Autonomy & 0.11 & $0.23^{*}$ \\
\hline \multicolumn{3}{|l|}{ Self-esteem } \\
\hline RSE & $0.22^{*}$ & $-0.65^{\star * * *}$ \\
\hline Mean diary & $0.37 * * * *$ & $-0.68^{* * * *}$ \\
\hline s.d. diary & -0.02 & 0.10 \\
\hline \multicolumn{3}{|l|}{ Pragmatic Interference Task } \\
\hline Positive & 0.20 & -0.14 \\
\hline Negative & -0.03 & 0.10 \\
\hline \multicolumn{3}{|l|}{ Autobiographical memory } \\
\hline Positive & -0.19 & -0.03 \\
\hline Negative & -0.13 & 0.00 \\
\hline \multicolumn{3}{|l|}{ RSQ } \\
\hline Rumination & 0.01 & $0.33^{* * * *}$ \\
\hline Adaptive coping & 0.14 & -0.16 \\
\hline Risk-taking & 0.16 & 0.00 \\
\hline \multicolumn{3}{|l|}{ BIS/BAS } \\
\hline BIS & $-0.20 *$ & 0.14 \\
\hline Drive & $0.32 * * *$ & -0.13 \\
\hline Fun seeking & $0.25^{\star}$ & 0.01 \\
\hline Reward responsiveness & $0.19 *$ & -0.05 \\
\hline CARROT, reward responsivity & 0.18 & 0.10 \\
\hline \multicolumn{3}{|c|}{ 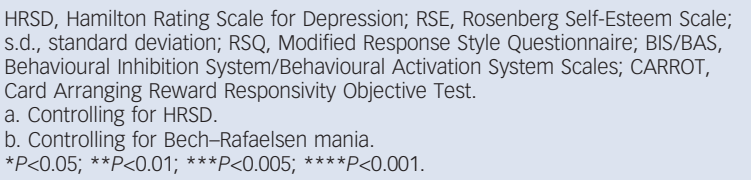 } \\
\hline
\end{tabular}


the negative cognitive style was still evident in the euthymia group, even after symptoms were controlled for. One possible interpretation of this finding is that negative cognitive style is a vulnerability factor in people with bipolar disorder that, when activated, leads to spiraling negative thoughts about self, rumination and eventually severe depression. By contrast, the factor we have characterised as excitement, consisting of high responsivity to reward signals and excessive risk taking, seems to be clearly state-related and associated with current mania.

The finding that bipolar depression and bipolar mania are related to distinct psychological processes is consistent with recent findings that have suggested that mania is not simply the opposite of depression. ${ }^{24,25}$ It is also consistent with the finding that depression and mania are provoked by distinct kinds of life events. $^{6,26}$

\section{Limitations}

A limitation of this study is that we were unable to take into account the effects of treatment on the psychological processes we were measuring. However, any such effects would reduce the variance in our data and thereby reduce our opportunity to demonstrate significant associations between the measures and psychopathology. A more important limitation is that the study was cross-sectional, and hence could not address the evolution of bipolar symptoms (an inherently dynamic process) over time. It has recently been suggested that neither depressogenic cognitive styles nor reward sensitivity are sufficient to account for the complexity of bipolar phenomena ${ }^{27}$ and that higher level cognitive appraisals play an important role in the ascent into mania. ${ }^{28}$ More complex longitudinal designs will be required to test these accounts.

\section{Implications}

The major clinical implication of the present study is that attention must be given to the two types of psychological processes we have identified when designing interventions for people with bipolar disorder. Given that dopaminergic function is implicated in the anticipatory processing of reward stimuli, ${ }^{29}$ it is unsurprising that dopamine-blocking drugs are effective in treating manic states. ${ }^{30}$ It might be useful to consider the effects of other pharmacological interventions, for example mood stabilisers, on negative cognitive styles and reward processing. In humans there is evidence that lithium and carbamazepine normalise self-esteem thereby preventing relapse. ${ }^{31}$ In animals, there is evidence that lithium can attenuate some dopamine-induced behaviours thought to be related to reward responsivity. ${ }^{32}$

With respect to psychological interventions, our recent trial of cognitive therapy yielded disappointing results ${ }^{33}$ and it might be argued that other trials ${ }^{34-36}$ have been more successful because they have more thoroughly incorporated techniques to prevent excessive responding to reward stimuli. Further advances in the psychological treatment of people with bipolar disorder are likely to be achieved following a more thorough understanding of the processes involved in the evolution of bipolar symptoms.

\footnotetext{
Emma Van der Gucht, MSC, Department of Clinical Psychology, University of Leeds; Richard Morriss, MD, Department of Psychiatry, University of Nottingham; Gill Lancaster, PhD, Postgraduate Statistics Centre, Department of Mathematics and Statistics, University of Lancaster; Peter Kinderman, PhD, Department of Clinical Psychology, University of Liverpool; Richard P. Bentall, PhD, School of Psychology, University of Bangor, Gwynedd, UK

Correspondence: Richard P. Bentall, School of Psychology, Adeilad Brigantia, University of Bangor, Gwynedd LL57 2AS, UK. Email: richard.bentall@bangor.ac.uk

First received 25 Nov 2007, final revision 14 Jul 2008, accepted 13 Aug 2008
}

\section{Acknowledgement}

This research was funded by a grant from Mersey Care NHS Trust.

\section{References}

1 Jones L, Scott J, Haque S, Gordon-Smith K, Heron J, Caesar S, et al. Cognitive style in bipolar disorder. Br J Psychiatry 2005; 187: 431-7.

2 Knowles R, Tai S, Jones SH, Highfield J, Morriss R, Bentall RP. Stability of selfesteem in bipolar disorder: Comparison among remitted bipolar patients, remitted unipolar patients and healthy controls. Bipolar Disord 2007; 6: 490-5.

3 Thomas J, Knowles R, Tai S, Bentall RP. Response styles in bipolar disorder. $J$ Affect Disord 2007; 100: 249-52.

4 Scott J, Pope M. Cognitive styles in bipolar disorder. Psychol Med 2003; 33: 1081-8.

5 Lyon $\mathrm{H}$, Startup M, Bentall RP. Social cognition and the manic defense. J Abnorm Psychol 1999; 108: 273-82.

6 Johnson SL, Sandow D, Meyer B, Winters R, Miller I, Solomon D, et al. Increases in manic symptoms after life events involving goal attainment. J Abnorm Psychol 2000; 109: 721-7.

7 Depue RA, lacano WG. Neurobehavioural aspects of affective disorders. Annu Rev Psychol 1989; 40: 457-92.

8 American Psychiatric Association. Diagnostic and Statistical Manual of Mental Disorders (4th edn, revised) (DSM-IV-TR). APA, 2000.

9 First M, Spitzer R, Gibbon M, Williams J. Structured Clinical Interview for Axis I DSM-IV Disorders. American Psychiatric Association, 1995.

10 Nelson H. National Adult Reading Test (2nd edn). nferNelson, 1991.

11 Hamilton M. A rating scale for depression. J Neurol Neurosurg Psychiatry 1960; 23: 59-62.

12 Bech P, Rafaelsen OJ, Kramp P, Bolwig TG. The Mania Rating Scale: scale construct and inter-observer agreement. Neuropharmacol 1978; 17: 430-1.

13 Cassidy F, Forest K, Murry M, Carroll BJ. A factor analysis of the signs and symptoms of mania. Arch Gen Psychiatry 1998; 55: 27-32.

14 Robins CJ, Ladd J, Welkowitz J, Blaney PH, Diaz R, Kutcher G. The Personal Style Inventory: preliminary validation studies of new measures of sociotropy and autonomy. J Psychopath Behav Assess 1994; 16: 277-300.

15 Carver CS, White TL. Behavioral inhibition, behavioral activation, and affective responses to impending reward or punishment: the BIS/BAS scales. J Pers Soc Psychol 1994; 67: 319-33.

16 Williams JMG, Broadbent K. Autobiographical memory in attempted suicide patients. J Abnorm Psychol 1986; 95: 144-9.

17 Winters KC, Neale JM. Mania and low self-esteem. J Abnorm Psychol 1985; 94: $282-90$

18 Rosenberg M. Society and the Adolescent Self-Image. Princeton University Press, 1965.

19 Knowles R, Tai S, Christensen I, Bentall R. Coping with depression and vulnerability to mania: a factor analytic study of the Nolen-Hoeksema (1991) Response Styles Questionnaire. Br J Clin Psychol 2005; 44: 99-112.

20 Powell J, Al-Adawi S, Morgan J. Motivational deficits after brain injury: Effects of bromocriptine in 11 patients. J Neurol Neurosurg Psychiatry 1996; 60: 416-21.

21 Kernis MH, Cornell DP, Sun CR, Berry A, Harlow T. There's more to selfesteem than whether it is high or low: The importance of stability of selfesteem. J Pers Soc Psychol 1993; 65: 1190-204.

22 Watson D, Clark LA, Tellegren A. Development and validation of a brief measure of positive and negative affect. J Pers Soc Psychol 1988; 54 1063-70.

23 Gorusch RL. Factor Analysis. Erlbaum, 1983.

24 Bauer MS, Simon GE, Ludman E, Unutzer J. 'Bipolarity' in bipolar disorder: distribution of manic and depressive symptoms in a treated population. Br J Psychiatry 2005; 187: 87-8.

25 Murray G, Goldstone E, Cunningham E. Personality and predisposition(s) to bipolar disorder: Heuristic benefits of a two-dimensional model. Bipolar Disord 2007; 9: 453-61.

26 Johnson SL, Meyer B, Winett C, Small J. Social support and self-esteem predict changes in bipolar depression but not mania. J Affect Disord 2000; 58: 79-86.

27 Power M. Psychological approaches to bipolar disorders: a theoretical critique. Clin Psychol Rev 2005; 25: 1101-22. 
28 Mansell W, Pedley R. The ascent into mania: a review of psychological processes associated with the development of manic symptoms. Clin Psychol Rev 2008; 28: 494-520.

29 Berridge KC, Robinson TE. Parsing reward. Trends Neurosci 2003; 9: 507-13.

30 Khanna S, Vieta E, Lyons B, Grossman F, Eedekens M, Kramer M. Risperidone in the treatment of acute mania. Double-blind, placebo-controlled study. Br J Psychiatry 2005; 187: 229-34.

31 Wolf R. Evaluation of several formulae for correction of item-tota correlations in item analysis. J Educat Measur 1967; 4: 21-6.

32 Beaulieu JM, Sotnikova TD, Yao WD, Kockeritz L, Woodgett JR, Gainetdinov $\mathrm{RR}$, et al. Lithium antagonises dopamine-dependent behaviors mediated by an AKT/glycogen synthase kinase 3 signaling cascade. Proc Natl Acad Sci USA 2004; 101: 5099-104.
33 Scott J, Paykel E, Morriss R, Bentall R, Kinderman P, Johnson T, et al. Cognitive-behavioural therapy for severe and recurrent bipolar disorders. Randomised controlled trial. Br J Psychiatry 2006; 188: 313-20.

34 Colom F, Vieta E, Martinez-Aran A, Reinares M, Goikolea JM, Benabarre A, et al. A randomized trial on the efficacy of group psychoeducation in the prophylaxis of recurrences in bipolar patients whose disease is in remission. Arch Gen Psychiatry 2003; 60: 402-7.

35 Lam DH, Hayward P, Watkins ER, Wright K, Sham P. Relapse prevention in patients with bipolar disorder: Cognitive therapy outcome after 2 years. Am J Psychiatry 2005; 162: 324-9.

36 Perry A, Tarrier N, Morriss R, McCarthy E, Limb K. Randomised controlled trial of efficacy of teaching patients with bipolar disorder to identify early symptoms of relapse and obtain treatment. BMJ 1999; 318: 149-53.

\section{Poems by doctors}

\section{Watching someone die}

\section{Lenrie Peters}

Watching someone die

is a fraudulent experience

The deep significance is felt

the meaning escapes

like a child's first punishment.

The dying ravish your strength

whether by throttle of convulsive gasp

or tideless fading away

like ancient familiar sounds in sea shells

the moment is the same

reinforced brutality to life

a rugged cliff bloodstained

with the agonising rhythm of many heads.

A cold demise; each

successive moment a banishment.

The terror is in leaving behind

the ache is in departing.

Humming fantasies crowd their stings

to seize and record the moment

the hands curl in spasm

to hold it back; this life, this infidel.

It is too late. Everything and nothing

has happened. A huge machine

the earth, grinds to a bolt-knocking halt.

It is the changing of the tide

at the boundary hour

Life like a handful of feathers

engulfed by cliff winds

one like yourself swept

Oh so swiftly into the anchorage of history

Tears and sighs; sighs and tears

stamping the leaden feet

the solid agony of years

they all abound.

one life or a million

contrived by nature or by man

greatly obscures the issue.

Face to face with dying

you are none-the-wiser

Yet it seems a most ignoble epitaph

'He was a man and had to die; after all.'

Lenrie Peters was born in Bathurst (Banjul), The Gambia, in 1932. He studied medicine at Trinity College Cambridge and later trained as a surgeon. He currently practises in The Gambia. He has been Chairman of the West African Examinations Council. He has published one novel, The Second Round, and four volumes of poetry - Poems (Mbari Press, 1964), Satellites (Heinemann, 1967), Katchikali (Heinemann, 1971) and Selected Poetry (Heinemann, 1981). He is the Officer of the Republic of the Gambia. This poem is taken from Satellites by kind permission of the author.

Selected by Femi Oyebode. 